\title{
A DIVERSIDADE DE REPRESENTAÇÕES DE MASCULINIDADES NA PUBLICIDADE ${ }^{1}$
}

\author{
Diversity of male representations in advertising \\ La diversidad de representaciones de masculinidades en la publicidad
}

Danilo Postinguel

Professor do FIAMFAAM - Centro Universitário

d.postinguel@gmail.com

\section{Resumo}

Tomando por inspiração a campanha publicitária "Find your magic", da marca de cosméticos Axe, propomos problematizar a diversidade de representações imagéticas de masculinidades ofertadas no anúncio publicitário e as reverberações na construção das identidades masculinas. $\mathrm{O}$ interesse surgiu devido a certa celebração que é propagada em torno de alguns anúncios publicitários pelo fato de estarem mais inclusivos e abertos à diversidade. Contudo, verificamos a ausência de uma "diversidade" de representações, e as que foram visibilizadas ainda eram apontadas pelos sujeitos como produzidas dentro de um regime estético e corporal, propiciando reforçar crises identitárias pelo não-reconhecimento de tais representações.

Palavras-chave: Representações de masculinidades. Comunicação Publicitária e Consumo. Estudos Culturais.

\begin{abstract}
This paper analyzes the "diversity" of imagery representations of masculinities in the advertising campaign "Find your magic" and the unfolding in the construction of masculine identities. The interest arose due to certain celebration that is propagated around some advertising campaigns because they are more inclusive and open to diversity. However, we verified the absence of "diversity" of representations, and those that were visualized were pointed out by the netizens as produced within an aesthetic and corporal regime, propitiating to reinforce identity crises by the non-recognition of such representations.
\end{abstract}

Key words: Representations of masculinities. Advertising and Consumption. Cultural Studies.

\section{Resumen}

Proponemos analizar la "diversidad" de representaciones de masculinidades en la campaña publicitaria "Find your magic" y los desarrollos en la construcción de identidades masculinas.

\footnotetext{
1 Versão revista e ampliada de trabalho apresentado no GT COMUNICAÇÃO, CONSUMO E NOVOS FLUXOS POLÍTICOS: ativismos, cosmopolitismos, práticas contra-hegemônicas, do $7^{\circ}$ Encontro de GTs de Pós-Graduação - Comunicon, realizado nos dias 10 e 11 de outubro de 2018.
} 
El interés surgió debido a una cierta celebración que se extiende alrededor de algunas campañas publicitarias debido al hecho de que ellas son más inclusivas y abiertas a la diversidad. Sin embargo, constatamos la ausencia de una "diversidad" de representaciones, y las que se hicieron visibles fueron apuntadas por los internautas como producidas dentro de un régimen estético y corporal, propiciando el fortalecimiento de las crisis de identidad por el no reconocimiento de tales representaciones.

Palabras clave: Representaciones de masculinidades. Comunicación Publicitaria y Consumo. Estudios Culturales.

\section{CONSIDERAÇÕES INICIAIS}

As representações de masculinidades na comunicação publicitária afiguram-se como a temática particular deste artigo; antes de conceituá-las, pensamos ser pertinente explanar nossos questionamentos e as escolhas investigativas que nos aproximaram desse objeto de pesquisa.

Nos últimos anos, adotando, por vezes, certo tom celebrativo, vimos florescer, via comunicação publicitária, uma pluralidade de representações, inclusive, de masculinidades. Recebidas com certo entusiasmo, essas produções midiáticas eram lidas por alguns segmentos da sociedade, como mais inclusivas, abertas à diversidade, entre outros predicados. De fato, comungamos que existe um movimento gradativo de atualização do campo publicitário em repensar seus produtos comunicacionais. Essa reivindicação é protagonizada por movimentos organizados, ativistas, pelas reflexões lançadas pelo campo científico e, até mesmo, pelo próprio campo prático da publicidade, reverberando um debate na agenda social, de políticas públicas e midiática.

Contudo, a discussão levantada não pode ser findada em compreender essas campanhas e seus anúncios como meros artefatos legitimadores de agências de publicidade e/ou engajamento de marca(s). Para nós, a publicidade deixa de ser mero instrumento mercadológico a serviço do capital, para ser entendida como um processo comunicativo, “cujas mensagens persuasivas são produzidas e recebidas em contextos contraditórios, implicados tanto pelo sistema hegemônico da estrutura econômica, quanto pelas práticas culturais dos sujeitos" (PIEDRAS; JACKS, 2006, p. 3).

Concatenando com a provocação de Stuart Hall (2003), o artigo busca problematizar o debate em torno da emergência de outras representações imagéticas de masculinidades oriundas da comunicação publicitária e as reverberações desse jogo de in/visibilidade no debate das identidades de gênero, em especial no que se refere ao debate das identidades masculinas, quando em interação com os sujeitos. 
Interessa-nos analisar como algumas representações imagéticas de masculinidades podem receber a recusa, enquanto outras representações são creditadas como aquelas que representam uma identidade masculina, observando quais fatores socioculturais, econômicos e comunicacionais-midiáticos estão aí implicados.

Assumimos para o debate a problematização em torno das relações de gênero a partir da mídia, pois, em primeiro lugar, o debate em torno das questões de gênero(s) e sexualidade(s) é um assunto efervescente e central em nosso contexto sociocultural. Segundo, e compreendendo a centralidade da mídia em nossa sociedade, é verificar o seu papel nos processos de atualização ou manutenção de representações e identidades.

Chamamos a atenção para a questão desses processos de visibilidade imagética serem tanto de atualização quanto de manutenção, pois em pesquisa recente ${ }^{2}$, divulgada pela agência de publicidade heads., "Todxs", menos de $20 \%$ dos comerciais analisados na pesquisa contribuíam para a equidade de gênero e raça no Brasil ${ }^{3}$. Das outras questões apuradas, pontuamos que mesmo sendo $25 \%$ dos comerciais da amostra protagonizada por homens, contra $16 \%$ por mulheres, são menos estereotipadas as representações masculinas do que em relação às femininas $(7,55 \%$ contra $14,91 \%$, respectivamente). No entanto, existe um chamamento maior de empoderamento para as mulheres $(5,45 \%)$ do que para os homens $(0,82 \%)$.

Essa observação em torno da "emancipação masculina e das masculinidades", de alguma forma já estava posta, em 2006, no levantamento feito por Escosteguy e Messa (2006). Na ocasião, o trabalho documentava a presença da temática das relações de gênero na pesquisa em comunicação. Por meio de um levantamento de dissertações e teses, defendidas nos PPGCOMs, durante os anos de 1992 e 2002, o estudo aferiu que, das pesquisas produzidas ao longo daquele decênio, foram inventariados apenas 65 trabalhos que adotavam a temática das relações de gênero como objeto de investigação e, desses estudos, apenas três contemplavam o "masculino" como objeto de estudo. Há a demanda como desdobramento, segundo as autoras, de uma maior atenção para as pesquisas que envolvam os estudos de recepção, a problemática da raça e o que nos toca, o universo masculino.

\footnotetext{
${ }^{2}$ heads. Todxs. 6. ed. Disponível em: $<$ https://drive.google.com/file/d/1_LGKWJ0211ElWp_ROJ1EONbfPILbElR-/view $>$.

${ }^{3}$ Cf. WALLAUER, Juliana. Menos de $20 \%$ dos comerciais contribui para a equidade de gênero e raça no Brasil. B9. Disponível em:<http://www.b9.com.br/61418/advertising/menos-de-20-dos-comerciais-contribui-para-aequidade-de-genero-e-raca-no-brasil/>. Acesso em: 13 jun. 2018.
} 
O mesmo resultado pôde ser observado em outro estudo desenvolvido por John e Costa (2014) a respeito do "universo masculino" nas pesquisas em comunicação. Os autores apresentaram, por meio de um estado da arte, os estudos de recepção que foram realizados no Brasil que articulavam a problemática das relações de gênero, tendo como foco as discussões sobre masculinidades. Ao fazerem o levantamento, que compreendia o decênio de 2000 a 2010, priorizando, também, as teses e dissertações defendidas pelos PPGCOMs, enfatizaram que "os resultados apontam a baixa presença das discussões que articulam gênero e recepção e para a ausência de estudos sobre masculinidades" (JOHN; COSTA, 2014, p. 61).

Nosso interesse investigativo em torno "das representações e identidades masculinas" não se resume apenas de preencher uma lacuna investigativa que se descortina, mas principalmente, ela reforça a necessidade de se aumentar essa discussão no campo da comunicação. Afinal, se debate e é pesquisado, no que se refere às relações de gênero, o papel da mulher na sociedade, mas poucas ainda são as discussões no campo da comunicação, que refletem como essa cultura machista, patriarcal, falocêntrica e falocrática, estereotipada na representação de um homem-branco-heterossexual, afeta não apenas as mulheres e sujeitos que possuem uma postura LGBT, mas afeta a todos, inclusive os homens. Cobrando-nos cautela ao endossarmos o coro celebrativo desses "anúncios mais inclusivos".

Para a realização de nosso estudo, adotamos como eixo condutor as reflexões provenientes dos Estudos Culturais, que, para Piedras e Jacks, adotar essa perspectiva viabilizaria não apenas a construção de uma abordagem processual, mas também cultural da publicidade, "capaz de envolver as instâncias da produção, da recepção e de seus discursos, em um único cenário, que permite explorar suas inter-relações” (2006, p. 3).

Acrescemos ainda, a partir de Ana Carolina Escosteguy, ser "impossível abstrair a análise da cultura das relações de poder e das estratégias de mudança social” (2014, p. 160). A asserção da autora reforça que as investigações feitas a partir do paradigma dos Estudos Culturais circunscrevem-se a temas vinculados à cultura popular e aos meios de comunicação e suas posteriores reverberações, relacionadas, por exemplo, com a identidade, sejam elas sexuais, de classe, étnicas, geracionais, entre outras.

Para acompanhar o percurso teórico que trilharemos nas páginas que se seguem, assumimos como objeto de análise a campanha publicitária "Find your magic", encomendada pela marca francesa Axe, pertencente a Unilever, à agência holandesa 72andSunny. O mote faz parte de uma campanha global da marca, difundida inicialmente por meio de um anúncio publicitário veiculado pelo YouTube em 12 de janeiro de 2016. 
Tomamos-a como um objeto empírico para esta reflexão, pois a campanha em questão exemplifica as provocações levantadas por Piedras e Jacks (2006), ao se referirem à comunicação publicitária e seus anúncios como um espaço que oferece possibilidades de se acessar determinadas questões da sociedade que os produz. Afinal, o objeto não apenas suscita um debate acerca da sociedade que os produz, como também enseja discussões em torno dos atravessamentos desses anúncios publicitários - e o seu consumo - em plurais dinâmicas socioculturais.

\section{COMUNICAÇÃO E CONSUMO: PROBLEMATIZANDO OS ESTUDOS CULTURAIS}

Inicialmente demarcamos que não é nossa intenção assumir a condução desta reflexão a partir de uma perspectiva lato da comunicação. Delimitamos nossa reflexão sobre a comunicação para compor o enlace com o consumo, a comunicação publicitária; portanto desvencilhados de uma perspectiva meramente maniqueísta do capital, a entendemos como uma narrativa que, inserida nas práticas sociais do cotidiano, reflete e refrata representações sociais e se torna cabedal para a construção das identidades.

Compreender a comunicação publicitária e seus anúncios como produtos culturais que são tramados em contextos socioculturais culmina na compreensão de analisar quais significados são mobilizados, quando em interação com os sujeitos munidos de seus repertórios culturais.

Essas análises, como afirmam Piedras e Jacks (2006, p. 4), já estavam nas reflexões de Raymond Williams na década de 1960, que "empreendeu uma análise social e histórica da publicidade, revelando que seu caráter comercial está vinculado a um sistema mágico de satisfação". Referente a essa instância "mágica da publicidade", relembramos o trabalho pioneiro de Everardo Rocha sobre as míticas do contemporâneo, publicado na década de 1980, que localizava nos anúncios publicitários um espaço "rico de possibilidades como via de acesso a determinadas questões da sociedade que os produz" (1995, p. 26).

Dessa forma, os anúncios publicitários, além de serem "um registro eloquente da experiência social [...] ensina modos de sociabilidade enquanto explica o quê, onde, quando e como consumir" (ROCHA, 2006, p. 11). Mais do que a oferta de consumo de mercadorias, possibilitam modos de sociabilidade, projetam estilos de vida e tornam-se referencial identitário, por meio do consumo de seus anúncios. 
Esse caráter pedagógico dos anúncios publicitários é possível, como atesta Douglas Kellner, pois nossa cultura contemporânea é dominada pela mídia. Suas imagens, sons, informações, entretenimentos e espetáculos, ao urdirem o tecido da vida cotidiana, tornam-se uma fonte, muitas vezes desapercebida de pedagogia cultural que "contribuem para nos ensinar como nos comportar e o que pensar e sentir, em que acreditar, o que temer e desejar e o que não" (KELLNER, 2001, p. 10).

Se o Estudos Culturais são essa investida na compreensão do papel da cultura nas sociedades, cultura essa entendida como "um campo de relações estruturadas pelo poder e por diferenças sociais" (ESCOSTEGUY, 2014, p. 151), Kellner nos chama a atenção para a participação da cultura da mídia nesses processos, principalmente em sua atuação no cotidiano. Valendo-nos das contribuições de Jesús Martín-Barbero para compreendermos essa relação que existe entre comunicação e cultura, tanto a cultura se torna uma mediação para se consumir e significar as produções midiáticas, quanto a mídia se torna uma mediação para se ler a sociedade.

Continuaremos problematizando a partir das contribuições de Douglas Kellner, mas demarcar, mesmo que brevemente nesse momento, as asserções de Jesús Martín-Barbero nos faz permanecer alertas referente à superação da unilateralidade da mídia e da passividade por parte de seus receptores. Afinal, e isso veremos mais adiante, não podemos nos esquecer dos usos e das apropriações que são feitas dessas produções pelos sujeitos.

Prosseguindo, conforme enfatiza Kellner, essa cultura da mídia possibilita nos ancorarmos e nela nos fazermos indivíduos, pois suas imagens forneceriam representações "daquilo que significa ser homem ou mulher, bem-sucedido ou fracassado, poderoso ou impotente" (2001, p. 9), demonstrando a força de agenciamento que podem ter os meios de comunicação analógicos, mas também os digitais, ao influenciar nossas vidas, identidades e subjetividades.

O trabalho de Kellner desvela as possíveis filiações que podem ser assumidas para compreender os Estudos Culturais. Não negamos suas contribuições para o campo e para a presente reflexão, contudo, e nesse esforço dialético, acrescemos uma discussão filiada à perspectiva latino-americana, que desloca as investigações do texto para o contexto, assim como traz a emergência dos estudos de recepção. Afinal, 
pensar a comunicação na América Latina é cada dia mais uma tarefa de envergadura antropológica. Pois o que aí está em jogo não são só deslocamentos do capital e inovações tecnológicas, mas profundas transformações na cultura cotidiana das minorias. [...] Mudanças que nos confrontam com uma acelerada desterritorialização das demarcações culturais e com desconcertantes hibridizações nas identidades (MARTÍNBARBERO, 2004, p. 209).

Néstor García Canclini, uma das principais referências dos estudos comunicacionais latinoamericanos, nos guia ao ampliar a noção de consumo. Para o autor, o consumo

\begin{abstract}
é o conjunto de processos socioculturais em que se realizam a apropriação e os usos dos produtos. Esta caracterização ajuda a enxergar os atos pelos quais consumimos como algo mais do que simples exercícios de gostos, caprichos e compras irrefletidas, segundo os julgamentos moralistas, ou atitudes individuais, tal como costumam ser explorados pelas pesquisas de mercado (CANCLINI, 1995, p. 53).
\end{abstract}

Pensar o consumo, sob esse prisma, é compreendê-lo desde suas expressões plurais, um consumo atravessado por fluxos comunicacionais, que transcendem a ordem do consumismo, do ato de consumir por consumir. Um consumo que demarca reconhecimento, aceitação, vinculação e existência. Consumir, além de ser uma prática mediada por fluxos comunicacionais, é participar de um cenário de disputa por aquilo que a sociedade produz e seus modos de significação (CANCLINI, 1995).

O consumo, para o autor, seria uma prática fundamental, contemporaneamente, para se compreender, por exemplo, a construção das identidades. Ele fornece outros modos de estabelecer as identidades e demarcar a diferença, atestando que foi-se o tempo em que as identidades eram construídas a partir de uma essência a-histórica. Hoje, elas são constituídas no consumo. Chamamos a atenção para as transformações tecnológicas da mídia e (consumo de) suas produções que, mais extensivas e intensivas entre as sociedades, tensiona as identidades antes fixadas em repertórios exclusivos de uma localidade (CANCLINI, 1995).

\title{
3 IDENTIDADES: PARA SE PENSAR AS MASCULINAS
}

Stuart Hall (2011) aponta que vivemos na contemporaneidade uma crise das identidades. Ela é decorrente do indivíduo moderno que, visto como sujeito unificado, hoje encontra-se fragmentado. Essa fragmentação seria oriunda do deslocamento de algumas 
mediações, velhos redutos da ideologia, como a família e a escola, que passaram a ser feitas pela mídia (MARTÍN-BARBERO, 1997), gerando, assim, a irrupção de novas identidades.

Diante do exposto, assumimos como questão norteadora para esta reflexão que a circulação de múltiplas representações imagéticas, no nosso caso, nos anúncios publicitários, possibilita o surgimento de novas identidades. Todavia, antes de prosseguirmos analisando a relevância das representações imagéticas na constituição das identidades masculinas, lançamos algumas reflexões referentes às discussões em torno do conceito de "Identidade". Para tanto, adotamos como suporte teórico reflexivo as obras de Stuart Hall (2003) e Néstor García Canclini (1995).

A identidade não se limita a um conceito essencialista a-histórico. Nossa compreensão, a partir de Hall (2003), aceita que as identidades, na contemporaneidade, não são unificadas, pelo contrário, são fraturadas e fragmentadas. Elas são construídas a partir da linguagem, das posições na estrutura social e nas práticas de consumo, por exemplo, ensejando sobre elas não a necessidade de se procurar por sua essência, mas sim de historicizá-la e conceituá-la, afinal elas estão em constantes transformações.

Tem a ver não tanto com as questões "quem nós somos" ou "de onde nós viemos", mas muito mais com as questões "quem nós podemos nos tornar", "como nós temos sido representados" e "como essa representação afeta a forma como nós podemos representar a nós próprios" (HALL, 2003, p. 108109).

O excerto de Hall é revelador "para se pensar" a relação entre representação e identidade, tendo aí um papel preponderante a mídia, que, por meio de suas imagens e discursos, visibilizam ou invisibilizam representações que terão impacto direto na constituição das identidades, possibilitando apreender o que outrora sinalizou Canclini acerca dos processos de disputa, principalmente na empreitada de refletir como que a representação que é feita de nós e para nós nos afeta.

Se o ato de consumir é participar de um cenário de disputas, inclusive de visibilidade versus invisibilidade, por meio, por exemplo, das representações imagéticas midiáticas, Hall estende nossa reflexão, enfatizando que esse jogo também pode ser observado no processo de construção das identidades, que por serem constituídas nesse cenário de disputas, elas são criadas por meio da diferença e não fora dela, demarcando as relações que se pode emergir entre um Eu, alguns Nós e Eles/Outros. 
Isso nos permite pensar em "Identidades", no plural, afinal se o processo de construção da identidade é feito na diferença. Outra questão importante que precisamos enfatizar é que, se a construção identitária é feita com base na diferença e não fora dela, isso significa problematizar não que uma identidade deva negar a outra, mas sim que uma identidade precisa da outra para existir. Acrescentamos que, em uma determinada forma identitária hegemônica de masculinidade ${ }^{4}$, por exemplo, haverá outras agrupadas em torno dela, sejam elas contra-hegemônicas e/ou não hegemônicas.

O debate se potencializa com os fluxos globais midiáticos que não apenas hibridizam ou causam a mestiçagem entre culturas, como apontam Canclini (2013) e Martín-Barbero (1997), respectivamente. Mas, e problematizando esses fluxos globais midiáticos a partir das campanhas publicitárias, elas não apenas se tornam um registro eloquente da sociedade que as produz, como também permitem, e é sobre o que nos debruçamos, investigar quais significados são construídos ao serem consumidas pelos sujeitos em contextos socioculturais diferentes daquele em que foi produzida (CANCLINI, 1995).

Isto posto, o papel da comunicação, para Canclini, também é basilar para se compreender como se configuram e renovam as identidades. Segundo o autor,

A clássica definição socioespacial de identidade, referida a um território particular, precisa ser complementada com uma definição sociocomunicacional. Tal reformulação teórica deveria significar, no nível das políticas "identitárias" (ou culturais), que estas, além de se ocuparem do patrimônio histórico, desenvolvam estratégias a respeito dos cenários informacionais e comunicacionais onde também se configuram e renovam as identidades (CANCLINI, 1995, p. 36).

\section{METODOLOGIA}

Instigados pelas reflexões de Piedras e Jacks (2006) em compreender a publicidade como processo comunicativo, cujas mensagens são produzidas e recebidas em contextos socioculturais contraditórios, interessa-nos analisar, a partir da emergência e da circulação de outras representações imagéticas de masculinidades nos anúncios publicitários e a partir desse jogo de in/visibilidade promovido pela esfera da produção, quais representações recebem a

\footnotetext{
${ }^{4}$ Entendemos por "masculinidades" "uma configuração de prática em torno da posição dos homens na estrutura das relações de gênero. Existe, normalmente, mais de uma configuração desse tipo em qualquer ordem de gênero de uma sociedade. Em reconhecimento desse fato, tem-se tornado comum falar de "masculinidades"" (CONNELL, 1995, p. 188). A partir de Connell, acrescemos ainda, que, uma determinada forma hegemônica de masculinidade tem outras masculinidades agrupadas em torno dela, sejam elas contra-hegemônicas ou não hegemônicas.
} 
recusa e quais são legitimadas como representações masculinas, quando em interação com os sujeitos.

Dessa forma, fizemos uma imersão em uma análise de inspiração etnográfica, assumindo um "posto de observação" barberiano (TOSCANO; REGUILLO, 1998). Realizamos um mapeamento ou, como sugere Martín-Barbero, um mapa noturno

[...] para investigar a dominação, a produção e o trabalho, mas a partir do outro lado: das brechas, do consumo e do prazer. Um mapa não como fuga, mas para o reconhecimento da situação das mediações e dos sujeitos. Para alterar o lugar de onde são formuladas as perguntas, para assumir as margens não como um tema, mas como enzima. Porque os tempos não são para sínteses e há muitas áreas da vida diária que são ainda inexploradas, e em cuja exploração não pode avançar sendo tateadas, sem um mapa ou apenas um mapa noturno (MARTÍN-BARBERO apud TOSCANO; REGUILLO, 1998, p. vii - tradução nossa).

Para tanto, optamos em realizar o presente mapeamento e posterior observação nas mídias sociais, assumindo como recorte empírico o Facebook, pois o protagonismo assumido pelas mídias sociais na vida cotidiana e nas relações sociais "vem sendo discutida como uma importante reconfiguração com implicações de diversas ordens, inclusive nas relações de tempo e espaço e nas vivências identitárias" (COGO; BRIGNOL, 2011, p. 76).

As mídias sociais, principalmente o Facebook, tornam-se lócus privilegiado que possibilita percorrer os rastros deixados pelos usuários, quando em interação com outros atores sociais, desvelando memórias coletivas e imaginários sociais. Nessas mídias, torna-se pujante o protagonismo dos sujeitos, sendo possível localizar as motivações que fazem com que eles atestem ou recusem determinadas produções midiáticas. Essas motivações, tanto de aceitação quanto de negação, se dão por meio de um processo de negociação permanente desses sujeitos com essas produções, que levam em consideração suas práticas sociais individuais e coletivas e suas experiências identitárias (COGO; BRIGNOL, 2011).

Elegemos para esta investigação o anúncio, e apenas ele, da campanha publicitária "Find your magic", da marca Axe. Sabemos que, ao optarmos por tal escolha empírica, abrimos mão de outras produções midiáticas tão ricas quanto para o debate, contudo enxergamos, nesse anúncio, esse jogo de in/visibilidade de representações imagéticas de masculinidades. Disso nos interessa, como postulamos no início da metodologia, analisar quais representações de masculinidades são legitimadas, quais são negadas, quais se tornam visíveis e quais ainda permanecem invisibilizadas. 


\section{CONTEXTUALIZAÇÃO E REFLEXÃO: A ANÁLISE}

A campanha publicitária "Find your magic", criada para promover as novas versões de algumas linhas de anti-transpirantes masculinos encomendada pela marca francesa Axe, pertencente ao grupo Unilever, consistia em um filme publicitário e peças que foram veiculadas em outdoors. Elaborada pela agência holandesa 72andSunny, a campanha propunha "aos homens serem as melhores versões de si mesmos, livres de preconceitos e com autenticidade" (PRADO, 2016).

No anúncio publicitário, via-se a celebração da diversidade masculina. Dava-se visibilidade, por meio dele, a uma gama de representações masculinas, sejam elas comportamentais, físicas ou sexuais, que, de algum modo tensionavam a representação hegemônica de masculinidade cristalizada nesses comerciais. "Magrelos", "cadeirantes", "nerds", "relacionamentos homoafetivos", "negros", "ruivos", "performers", entre outras representações, protagonizavam o anúncio (Figura 1).

Em um primeiro momento, é possível fazer uma leitura de que o anúncio promove uma reflexão sobre as masculinidades (representações e identidades), ao ir na contramão das propagandas de desodorantes que trata(va)m o produto como mero artifício para conquistar mulheres, reforçando, na maioria das vezes, um tipo - e ideal - de representação de masculinidade e de homem. Isso pode ser reforçado com a transcrição da narrativa do comercial, a seguir reproduzida.

\section{Tanquinho? Fala sério!}

Quem precisa de tanquinho quando você tem o nariz?

Ou de nariz quando você tem esse estilo?

Você não precisa de estilo quando tem o suingue.

Nem suingue quando você tem atitude.

Ou atitude quando você arrasa no salto alto.

Pra quê salto alto quando você tem rodas?

Boa pinta?

Cara, quem precisa de boa pinta...

... quando você tem conteúdo?

Ou conteúdo quando você tem colhões?

E quem precisa disso tudo se você tem a manha?

Se você manda muito.

Se você tem o cérebro.

O toque,

$\mathrm{O}$ OHHH.

É, quem precisa de outra coisa quando você tem a sua? 


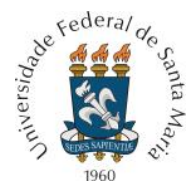

PROGRAMA DE PÓS-GRADUAÇÃO EM COMUNICAÇÃO DA UNIVERSIDADE FEDERAL DE SANTA MARIA

Então vai, deixa no jeito.

Publicado na fanpage brasileira $^{5}$ da marca em 19 de abril de 2016, até o dia da coleta (20 de maio de $2017^{6}$ ), contava com quase 15 mil compartilhamentos, mais de 70 mil curtidas (entre as opções "curtir", "amei" e "uau"), 3.800 comentários e mais de 5,8 milhões de visualizações.

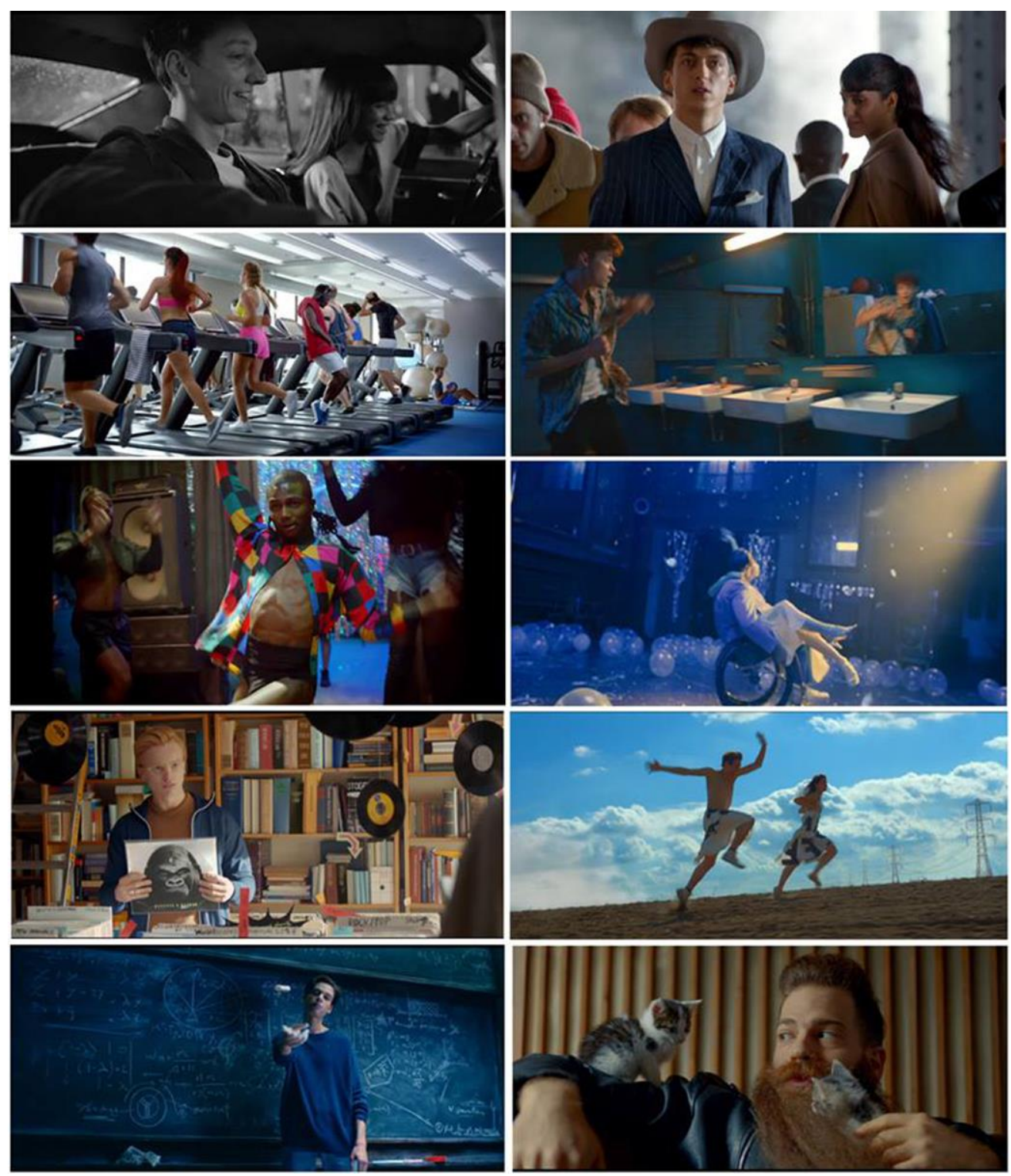

Figura 1 - Frames do anúncio publicitário "Find your magic"

Fonte: Elaborado pelo autor.

\footnotetext{
${ }^{5}$ Disponível em:<https://www.facebook.com/axebr/videos/10154464790482841/>. Acesso em: 17 jun. 2018.

${ }^{6}$ Os valores levantados na data da coleta não sofreram alterações até a data de submissão. Nova consulta realizada em: 15 out. 2018.
}

\section{ANIMUS Revista Interamericana de Comunicação Midiática E-ISSN 2175-4977 | v.18 n.38 | 2019 | www.ufsm.br/animus}


Analisando os números, é possível deflagrar que a campanha em questão gerou um burburinho expressivo na mídia. A partir dessa perspectiva quantitativa, a campanha, por meio do anúncio em questão, poderia ser enquadrada como uma campanha publicitária inclusiva, ao promover a diversidade de representações imagéticas masculinas. Contudo, quando em interação com os sujeitos, esse anúncio desvela outras leituras.

Durante o processo de mapeamento e análise dos comentários feitos nessa publicação, percebemos o agrupamento em cima de três grandes categorias: 1) da interação com os produtores do anúncio, 2) da mercadoria em questão e 3) da crítica sobre a narrativa, culminando em reações tanto positivas quanto negativas.

Nosso propósito foi o de analisar quais enfrentamentos podem existir de sentido, de representação, de visibilidade a partir de uma produção midiática; para tanto, concentramonos em analisar os primeiros 500 comentários $^{7}$ que o próprio Facebook nos forneceu. Essa opção já é uma parte do processo de análise, afinal já existe uma gestão do visível aí localizada, afinal quais são os critérios estipulados por essa mídia para tal ordenamento? Data de publicação? Quantidade de comentários? Quantidade de curtidas? Ou seja, nossa análise já é uma análise mediada por uma determinação tecnologia.

1) Da interação com os produtores do anúncio.

Um dado curioso foram os comentários que não apenas validavam o anúncio, mas, principalmente, seus produtores - na figura dos publicitários e/ou profissionais de marketing. Em algumas postagens, a euforia estava destinada mais para o profissional que produziu esse anúncio, do que propriamente para o seu conteúdo. Um exemplo é o comentário do Ator A: "Namoral e por causa destes comerciais, que eu quero fazer publicidade ou marketing, Voces mandaram muito bem, olha que nem uso muito a marca, Mais o pessoal de publicidade e marketing tão de parabens, Espero logo ver na tv". O comentário, por exemplo, é revelador, no sentido de apresentar que o Ator A não usa a marca. O consumo, aqui, é meramente do anúncio, que transporta suas dimensões mágicas (ROCHA, 1995), para quem o produz.

Em contrapartida, localizamos comentários que cobravam desse tipo de produção midiática uma postura mais social, que era sabido que o único propósito daquele anúncio era o de vender. Isso pode ser localizado em postagens, como as do Ator B, por exemplo:

\footnotetext{
7 Concentramo-nos nos primeiros 500 comentários, pois os demais tratavam-se de comentários em que internautas marcavam outros perfis para terem conhecimento da produção audiovisual publicitária, gerando marcações, mas não interações/discussões entre perfis e a marca, por exemplo.
} 


\begin{abstract}
"Onde estará a auto-estima? num carro de marca? na beleza física do corpo? ou no desodorante que você usa? Na publicidade intitulada: "O Roubo da Beleza" estrelada pelo ator Rodrigo Hilbert quem não tem o padrão estético do ator que estrelou a anúncio publicitário só poderá encontrar "o sucesso" fazendo o uso da fragrância anunciada. Já no anúncio postado acima pela marca AXE, "A magia" deve ser encontrada dentro de si mesmo. Paradoxal não é? Qual mensagem é a ideal? Claro que não devemos ser ingênuos, as duas publicidades só tem um mesmo objetivo: vender. Porém é necessário refletir no tipo de sociedade que isso ajuda a formar. Numa sociedade em que temos um alto índice de pessoas (sobretudo jovens e adolescentes) com graves crises de identidade, e também altos indices de depressão relacionadas a aparência, haja vista problemas decorrentes de saúde mental como anorexia e bulimia, sem contar o hábito cada vez mais crescente de cirurgas plásticas por menores de idade; o que devemos nos perguntar é qual o papel social que a publicidade das grandes marcas devem ter. Abaixo, para reflexão estão alguns artigos do Código Brasileiro de Autorregulamentação Publicitária do CONAR (Conselho Nacional de Auto Regulação Publicitária) [...]"'.
\end{abstract}

Reapresentamos o excerto problematizado no comentário: "o que devemos nos devemos nos perguntar é qual o papel social que a publicidade das grandes marcas devem ter". A provocação do Ator B apenas vai ao encontro da pesquisa realizada pela agência heads., de que ainda são poucos os comerciais que promovem o debate de forma eficaz em torno dos gêneros. Um ponto positivo é perceber como existe essa reivindicação por parte da sociedade, de uma publicidade mais consciente, que, de fato, suscite reflexões, localizando uma brecha para se pensar a publicidade enquanto um possível agente de transformação social.

2) Da mercadoria em questão.

Existiram alguns atores que, em interação com o anúncio, problematizavam mais o consumo da mercadoria do que da publicidade. Entre as reclamações, constavam a não disponibilidade em algumas localidades, curta duração, (re)lançamento de versões antigas, entre outras questões que podem ser observadas na postagem do Ator C: "Que belo comercial... Muito bom... Quanto a qualidade do produto, eu não me dou muito com axe... Tem alguns que são ótimos, tem outros que não... Mas isso é gosto pessoal...".

No entanto, também localizamos a importância do consumo do anúncio, para o posterior consumo da mercadoria, como observou em sua pesquisa Rocha (1995). Foi o caso do Ator D: "Deixei de usar Axe tem muito tempo, mas confesso que essa excelente 
propagando me tentou a voltar a usar. Excelente comercial". Mas a questão não se finda no consumo do anúncio que reverbera no consumo da mercadoria. Vemos aí a força de agenciamento que ainda pode ter a publicidade, tendo como possível desdobramento mensurar o engajamento que pode ter, ao consumo de mercadorias, anúncios que colocam em circulação questões sociais.

3) Da crítica sobre a narrativa.

Nesta categoria compreendemos, como sugere Escosteguy (2014), a cultura como esse lugar tenso, marcado por relações estruturadas pelo poder e por diferenças sociais, o papel da comunicação midiática e quais leituras - significados - são feitas desse consumo midiático.

A partir do corpus analisado, foi possível constatar que existiram muitos comentários que celebravam o anúncio publicitário. Em sua maioria, enalteciam o posicionamento da marca ao dar visibilidade para representações imagéticas de masculinidades que antes não protagonizavam tais anúncios, como pode ser verificado no comentário do Ator E: “ $A$ criatividade foi bem explorada assim como a diversidade, parabéns à toda equipe da AXE Brasil! Não uso os produtos da marca, mas campanhas assim despertam a curiosidade".

Outras interações eram ainda mais específicas. Algumas reforçavam essa preocupação, também apontada por Hall (2003), de compreender como "nós temos sido representados". É o caso do comentário do Ator $\mathbf{F}$, que vê seus amigos serem representados em uma publicidade. Segundo a postagem: "ótimo comercial e ótimo produto uso sempre, parabéns axe pela campanha, tenho um amigo cadeirante feliz como o do comercial, ele não tem barriga tanquinho mais e muito feliz, não tinha visto esse comercial, passa na tv?". Outro exemplo é o localizado no Ator G, que celebra a presença da diversidade sexual masculina, também no anúncio. "[marca outro perfil na postagem]... Tem bicha bichérrima e casal gay indie... adorei".

A postagem do Ator $\mathbf{F}$, assim como a de alguns outros, trouxe outro dado revelador de pesquisa. Essas postagens indagam à marca se o comercial em questão estava sendo veiculado na TV. Isso mostra o papel que ainda tem a televisão no Brasil como esse legitimador de inúmeras questões. Ou seja, para ter visibilidade e ser legitimado precisa passar na TV, sugerindo como ainda os meios com funções massivas medeiam as dinâmicas socioculturais.

Outro comentário oportuno que cabe pontuar aqui foi o do Ator $\mathbf{H}$, que vai ao encontro da nossa justificativa pelo tema das identidades e representações de masculinas. Para ele, esse comercial mostra que não é apenas as mulheres que sofrem com essas representações 
hegemônicas que servem de cabedal para as identidades. O mesmo ocorre com os homens, segundo o próprio ator: "Muito legal e mostrou q não é só mulher q sofre com o tipo perfeito a ser seguido".

Todavia, muitos outros comentários criticavam o comercial. Entre as alegações, estavam a de que aquela narrativa não passava de mera estratégia mercadológica de vendas, como também aquelas postagens que enxergavam o processo tanto de invisibilidade de representações de masculinidades, quanto aqueles sujeitos-internautas que não se viam representados ali. A crítica maior pairava na invisibilidade dos "gordinhos". Segundo alegam os internautas, em um anúncio que celebra a diversidade, não colocar uma representação de homem gordo apenas reforçava o padrão estético que ainda existe em nossa sociedade. Como foi o caso do Ator I: "Quero deixar aqui meu parecer em nome dos gordos que, para nos não tem jeito, e, a marca axe acaba de enterrar e confirmar, que gordo não pega mulher e não tem nada de bom".

Outra postagem, além de reforçar a ausência dos "gordinhos", reivindicava a visibilidade dos homens trans. Segundo a postagem: "Parabéns por ter pensado nas pessoas com deficiência. Além do gordinho não esqueçam que homens não precisam ter culhões e nem pinto. Tem trans homem não operado também" (Ator J). Também existiram aqueles que não se identificaram com as representações, ali apresentadas, como foi o caso do Ator L: "Gostei do Comercial, Axe, sempre usei ele, suas fragancias são as melhores do mercado. num sou gordinho, num sou narigudo, muito menos tenho cabelos ruivos, mas sempre tive meu reconhecimento, e sempre sou elegiado "nossa, como vc é cheiroso"”,

Foram poucos, mas pudemos verificar a presença, conscientemente ou não, de preconceitos, principalmente na representação imagética do performer. A principal crítica se dava pelo fato de um "homem" incorporar mercadorias e trejeitos "femininos". Como foi o caso do comentário do Ator M: "Homem” de salto alto e dançando que nem boiola? Me desculpem, mas esse tipo de influência está decaindo o produto que usava Jeremias eu um ser Viril e hétero e pegador de muitas mulheres nas propagandas..”. Já o comentário do Ator $\mathbf{N}$, por exemplo, adotava como sinônimo para a diversidade identitária o uso do termo "segmentação social”, para explicar a bela ação da marca: "hummm, comercial bem atual, seguindo a segmentação social e inspirando valores esquecidos como a individualidade e auto-estima, parabéns!!! muito bom". Ênfase para o emprego da palavra "segmentação" e não "diversidade". 
Esse tipo de circulação de representações plurais de masculinidades, por exemplo, estaria promovendo uma "crise de identidade" (Ator B) em nossa sociedade, principalmente na juventude, devido à imposição de padrões estéticos e corporais, segundo a postagem do Ator $\mathbf{O}$, "Não precisa de tanquinho Axe?, propaganda infeliz todos os atores são magros e seguem o padrão de beleza que a sociedade e especialmente a indústria cosmética nos impõe, esse tipo de marketing só mostram como vocês ditam para a maioria da massa suas regras estéticas e corporais, só menino "bonitinho" e padronizado, “contradição” é mato...”.

Encaminhando-nos para os últimos apontamentos de nossa análise, foi possível constatar no corpus coletado baixíssima participação do público feminino: dos 500 primeiros comentários fornecidos pelo Facebook para a análise, não chegavam a 10 as postagens do público feminino. Contudo, entre eles, destacamos o da Ator $\mathbf{P}$ que parabeniza a marca ao dar visibilidade para a diversidade masculina, segundo a postagem: “AMEI o comercial, é a primeira vez que vejo um comercial voltado pra diversidade masculina, um tão interessante e dinâmico! Parabéns AXE Brasil. Até EU uso Axe, o Black, é o melhor pra mim <3 Não parem de fabricar o melhor desodorante que já encontrei em 30 anos!".

Acrescemos ainda que foram poucas as postagens que geravam discussões entre outros internautas. A maioria concentrava a interação entre internauta e marca. As maiores discussões estavam nas postagens que criticavam o anúncio, principalmente no que se referia à invisibilidade de algumas representações, e a principal discussão que emergia era que "lá vem o ativista".

Outro dado curioso é o desinteresse, se pudermos nomear assim, das representações de masculinidades negras. Das 13 representações que foram apresentadas, apenas 3 eram de homens aparentemente negros/mulatos, inclusive o performer com indumentárias e trejeitos femininos. Não foi localizado em nosso corpus um debate de mais visibilidade e/ou maior representatividade.

Também não vimos serem questionadas representações mais abrasileiradas ou latinas, já que se tratava de uma campanha produzida na Holanda. Apenas em um comentário foi possível localizar "que não se tratava de uma propaganda brasileira", mas se encerrava a discussão aí. Isso pode indicar como existe uma cultura capitaneada pela mídia, para lembrarmos Kellner, que consegue circular por contextos socioculturais diferentes daquele de origem sem encontrar grandes empecilhos de circulação e consumo. Sugerindo que o processo de construção de identidades não se restringe às bases referenciais históricas e apenas locais; 
mais do que nunca, hoje esse processo é atravessado pelo consumo de fluxos comunicacionais globais.

\section{CONSIDERAÇÕES FINAIS}

Este artigo surgiu a partir da vontade de problematizar sobre a comunicação publicitária, principalmente no que se refere a uma certa celebração que existe atualmente em anúncios publicitários que abraçam a diversidade, dando visibilidade para outras representações de masculinidades, outrora insivibilizadas. Assumimos para esta reflexão a comunicação publicitária, respaldados por Piedras e Jacks (2006), como processo comunicativo que produzido e recebido em contextos contraditórios podem fornecer profícuas reflexões das sociedades e dos sujeitos.

Filiados ao paradigma dos Estudos Culturais, buscamos mapear a partir do enlace comunicação e consumo as relações de poder e as diferenças sociais que ainda pairam em nosso contexto sociocultural.

Sem dúvida, um dos apontamentos que ficam é referente à questão da diversidade oferecida. Por se tratar de uma campanha global, o anúncio fica devendo outras representações imagéticas de masculinidades que são localizadas no cotidiano. Os próprios internautas levantaram a questão da invisibilidade dos homens trans, como também, e principalmente, a ausência de representações que fugiam desse regime estético e corpóreo que a marca ainda reitera - corpo magro. A análise e posterior reflexão são sinérgicas com a pesquisa da agência heads., e, por mais que a campanha e o anúncio publicitário em questão promovam o debate em torno da diversidade masculina, ainda invisibilizam uma outra gama de representações de masculinidades.

Em nossa investigação, outro dado curioso, se pensarmos em uma cultura que é promovida pela mídia, é que, mesmo assumindo o protagonismo da esfera midiática, em especial das mídias sociais, na vida cotidiana e nas relações sociais, a TV ainda é em nossa cultura um agente legitimador e que dá visibilidade para campanhas publicitárias e as reflexões que promove. Dito de outro modo, para existirem é como se as campanhas precisassem ser veiculadas na TV, não bastaria circular pela internet.

Por fim, as implicações que essas representações podem surtir no processo de construção, seja de manutenção ou atualização, das identidades masculinas podem culminar em crises identitárias (HALL, 2011), como comenta enfaticamente um internauta, afinal ainda 
existe uma gestão mais homogeneizante, estética e corpórea dessas masculinidades que se tornam visíveis.

\section{REFERÊNCIAS}

CANCLINI, N. G. Culturas híbridas: estratégias para entrar e sair da modernidade. 4. ed. São Paulo: Editora da Universidade de São Paulo, 2013.

UFRJ, 1995.

Consumidores e cidadãos: conflitos multiculturais da globalização. Rio de Janeiro: Editora

COGO, D.; BRIGNOL, L. D. Redes sociais e os estudos de recepção na internet. Matrizes, São Paulo, v. 4, n. 2, jan./jul.. 2011. p. 75-92. Acesso em: 11 jun. 2018.

CONNELL, R. W. Políticas da masculinidade. Educação \& Realidade, Porto Alegre, v. 20, n. 2, p. 185-206, jul./dez. 1995. Acesso em: 15 out. 2018.

ESCOSTESGUY, A. C. D.; MESSA, M. R. Os estudos de gênero na pesquisa em comunicação no Brasil. Contemporânea, Salvador, v. 4, n. 2, p. 65-82. dez. 2006. Acesso em: 14 jun. 2018.

ESCOSTEGUY, A. C.. Os estudos culturais. In: HOHLFELDT, A.; MARTINO, L. C.; FRANÇA, V. V. (orgs.). Teorias da comunicação: conceitos, escolas e tendências. 14. ed. Petrópolis, RJ: Vozes, 2014.

HALL, S. A identidade cultural na pós-modernidade. 11. ed. Rio de Janeiro: DP\&A, 2011.

Quem precisa da identidade? In: SILVA, Tomaz Tadeu da (org.). Identidade e diferença: a perspectiva dos estudos culturais. 2. ed. Petrópolis, RJ: Vozes, 2003.

JOHN, V. M.; COSTA, F. Estudos de recepção sob a ótica das masculinidades: uma lacuna nas pesquisas de comunicação brasileiras. Novos Olhares, São Paulo, v. 3, n. 1. 2014. Acesso em: 14 jun. 2018.

KELLNER, D. A cultura da mídia - estudos culturais: identidades e políticas entre o moderno e o pós-moderno. Bauru: EDUSC, 2001.

MARTÍN-BARBERO, J. Ofício de cartógrafo: travessias latino-americanas da comunicação na cultura. São Paulo: Edições Loyola, 2004.

1997.

Dos meios às mediações: comunicação, cultura e hegemonia. Rio de Janeiro: Editora UFRJ,

PIEDRAS, E. R.; JACKS, N. A contribuição dos estudos culturais para a abordagem da publicidade: processos de comunicação persuasiva e as noções "articulação" e "fluxo". E-compós, Brasília, v. 6, 2006. Acesso em: 12 jun. 2018.

PRADO, L. Find your magic: Axe apresenta novo posicionamento em campanha global. CLUBE DE CRIAÇÃAO. 2016. Disponível em:<http://www.clubedecriacao.com.br/ultimas/find-your-magic/>. Acesso em: 16 jun. 2018.

ROCHA, E. Representações do consumo: estudos sobre a narrativa publicitária. Rio de Janeiro: Ed. PUC-Rio: Mauad, 2006. 
$\overline{1995 .}$

Magia e capitalismo: um estudo antropológico da publicidade. 3. ed. São Paulo: Brasiliense,

TOSCANO, M. C. L.; REGUILLO, R. (orgs.). Mapas nocturnos: diálogos con la obra de Jesús Martín-Barbero. Santafé de Bogotá: Siglo del Hombre Editores, Universidad Central. Departamento de Investigaciones, 1998.

Original recebido em: 15 de outubro de 2018

Aceito para publicação em: 16 de junho de 2019

Danilo Postinguel

Doutor e mestre em Comunicação e Práticas de Consumo (PPGCOM-ESPM). Pesquisador do grupo JUVENÁLIA: questões estéticas, geracionais, raciais e de gênero na comunicação e no consumo (ESPM-CNPq). Professor do FIAMFAAM - Centro Universitário.

\section{(ब) $\odot \odot$}

Esta obra está licenciado com uma Licença

Creative Commons Atribuição-NãoComercial-CompartilhaIgual 4.0 Internacional 